\section{Light on butterfly mating}

SIR - The existence of extraocular photoreceptors is widespread within the animal kingdom ${ }^{1}$. In arthropods such receptors exist in various parts of the body ${ }^{2-7}$, but their function is unknown in any species. Here we demonstrate that the light sense of genitalia in butterflies, which is mediated by two pairs of photoreceptor neurons (genital photoreceptors) ${ }^{8,9}$, is crucial in achieving copulation.

The mating behaviour of the Japanese yellow swallowtail butterfly, Papilio xuthus, consists of six steps. The male first approaches a female (step 1), and gets into the 'venter-to-venter' position with the female, often opening the valva, the structure with which he supports her genitalia from the side during copulation (step 2). He then searches the female's genitalia by touching her abdomen with his own genitalia exposed between the fullyopened valva (step 3), firmly clasps her scaphium $^{8}$. When the male has located the female's genitalia correctly (step 4), he inserts the penis, ejaculates, and then plugs the vagina with a sphragis by keeping the 'end-to-end' copulatory posture (step 5, Fig. 1), after which the pair finally separates (step 6).

Copulation requires precise alignment of the genitalia. How do butterflies confirm the alignment? What happens if the light sense of the genitalia is removed? We tested the effect of ablation of P1s, one of two pairs of genital photoreceptors, on mating behaviour. We bilaterally ablated P1s either by applying heat with a fine heat probe or by painting black material on the P1 site.

Figure 2 summarizes our results: $66 \%$ of the intact males successfully copulate (copulation success rate $=66 \%$ ) with intact vir-

FIG. 2 Effect of P1 ablation on mating behaviour in males. Black bar, successfully copulated; hatched bar, stopped at step 3 (the search for female's genitalia); white bar, failed to perform mating behaviour. Male P1s were bilaterally ablated either by treating the P1 site with heat or by painting the whole scaphium with black mascara. The percentage of males that failed to perform mating behaviour (white bar) is not significantly different between treatments, indicating that there is no effect on the

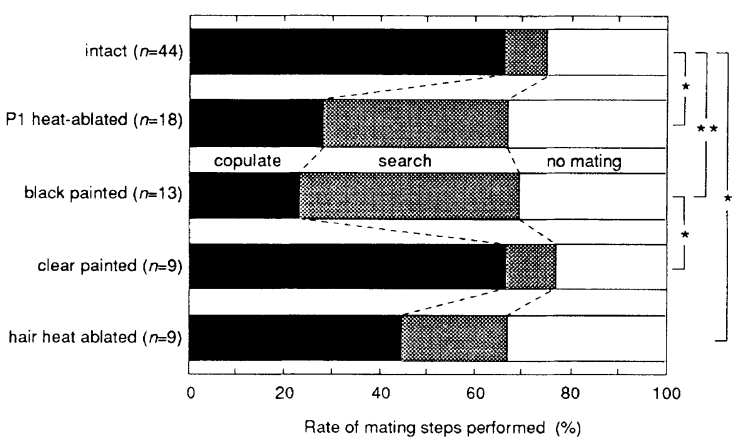

motivation for mating. We also ablated mechanoreceptive hairs on the scaphium, which was done by heating the receptor cell bodies from outside with a fine heat probe. The behavioural experiments were done in an outdoor cage $(11 \times 7 \times 3 \mathrm{~m})$. Ten to twelve intact virgin females were positioned in the cage by attaching the dorsal cuticle of the thorax with beeswax to the bottom end of an insect pin whose upper end was fixed to a horizontal bar set $2 \mathrm{~m}$ above the ground. We subsequently released 3-7 treated males. For each male, we recorded the behavioural step at which mating behaviour stopped. Mann-Whitney U-test was used for analysing the statistical difference in success rate between treatments $(*, P<0.01 ; * *, P<0.05)$. intact or control males where P1s are covered with clear paint. We found that $46 \%$ of the black-painted males stop mating behavour at step 3. These results uggest that males require of the genitalia during copulation. P1 ablation in females does not affect the copulation success rate of the treated females with

thas been tempting to is basically controlled by the mechanical sense of the genitalia ${ }^{10}$. The success rate of males whose mechanoreceptors on the scaphium are heat-ablated reduces to $44 \%$, indicating the necessity of mechanical sense for achieving This may P1 heat-ablated males can still copulate: males locate females' genitalia by using the mechanical sense. We note that another pair of genital photoreceptors, the P2s (ref. 8), may also contribute to mating behaviour, although this possibiliy has not yet been tested.

How do P1s control mating behaviour? To address this question, we electrophysiologically recorded the P1 response from
ol address this question, we electrophysigenitalia by using the superuncus and

mating males and revealed that the response sharply drops when the male correctly locates the female's genitalia. We therefore hypothesize that the drop in the $\mathrm{P} 1$ response informs the male that the female's vagina is correctly positioned for penis insertion. If the genitalia are not correctly aligned, the coupling would be incomplete, leaving some space through tact males. which light can enter, so that the P1 response continues. In this case, we presume that the male releases the clasp and goes back to the search step. The males with P1 painted black never experience such a response drop as there is little P1 activity to begin with, but continue the genitalia search even when the female's genitalia are correctly aligned, until they finally give up.

\section{K. Arikawa}

D. Suyama

T. Fujii

Graduate School of Integrated

Science,

Yokohama City University,

22-2 Seto, Kanazawa-ku,

Yokohama 236, Japan.

1. Yoshida, M. in Handbook of Sensory Physiology (ed. Autrum, H.) 582-640 (Springer, Berlin, 1979).

2. Ichikawa, T. Zool. Sci. 8, 471-476 (1991).

3. Kennedy, D. J. gen. Physiol. 46, 551-572 (1963).

4. Maitland, D. P., Heitler, W. J. \& Laverack, M. S. J. comp. Physiol. A 168, 513-520 (1991).

5. Sandeman, D. C., Sandeman, R. E. \& de Couet, H. G. J. Neurobiol. 21, 619-629 (1990).

6. Thompson, K.S J. \& Bacon, J.P. J. comp. Physiol. A 168, 619-630 (1991).

7. Yamashita, S. \& Tateda, H. J. comp. Physiol. 150 , 467-472 (1983).

8. Arikawa, K., Eguchi, E., Yoshida, A. \& Aoki, K. Nature 288, 700-702 (1980).

Miyako, Y., Arikawa, K. \& Eguchi, E. J. comp. Neurol. 327, 458-468 (1993).

10. Silberglied, R. E. in The Biology of Butterflies (eds VaneWright, R. I. \& Ackery, P. R.) 207-223 (Academic, London, 1984). 